\title{
Is There a Need for an International Mechanism of Scientific Expertise on Biodiversity?
}

The gap between biodiversity science and public policy must be urgently closed; and to do that, the world's science community must be far more strongly organized and integrated. Virtually all aspects of biodiversity are in steep decline and a large number of populations and species are likely to become extinct in the present century. Despite this evidence, biodiversity is still consistently undervalued and given inadequate weight in both private and public decisions. To address this issue, there is an urgent need to bridge the gap between science and policy.

For the sake of the planet, biodiversity science community has to create a way to get organized, to co-ordinate its work across disciplines, and together with one clear voice advise governments on steps to halt the potentially catastrophic loss of species already occurring. Biodiversity is intrinsically more complex than issues such as the stratospheric ozone hole or global climate change, because it spans several levels of biological organization, from genes to ecosystems, and cannot be measured by simple universal indicators, such as temperature and atmospheric $\mathrm{CO}_{2}$ concentration. In the long run, the loss of biodiversity and of associated ecosystem services may be a serious threat to human well-being, yet biodiversity is still perceived as a second-rate issue (compared, for example, with climate change), and current efforts have not been able to reverse the trend towards biodiversity loss.

Scientists working in the broad umbrella covered by global climate change say they managed to close the gap between science and police makers by speaking with a single authoritative voice through the Intergovernmental Panel on Climate Change (IPCC). On the other hand, existing organizations such as the Convention of Biological Diversity do not have the structural means to mobilize the expertise of a large scientific community that spans a wide range of disciplines. Therefore, biodiversity scientific community itself is still fragmented and poorly involved in the political process.

The climate change panel, the International Assessment of Agricultural Science and Technology, the Ozone Assessment Panel and other scientific collaborations today provide worthy examples of the sort of device needed. Each model has strengths and weaknesses but essentially they all serve as a reliable source of information and advice for the public, their governments and decision-makers, who then decide what to do. Professor Michel Loreau, President of DIVERSITAS says "We need diversity of opinions and approaches but we also need unity behind this collective effort, to speak with one voice globally when it comes to recognizing key issues and how they can best be addressed." Biodiversity provides ecosystem services such as disease and climate regulation, storm protection and habitat for useful species. "The loss of biodiversity imposes real economic costs on society, and we need to develop clear science guidance for policy options accordingly," says Charles Perrings of Arizona State University, USA and Vice-Chair of DIVERSITAS.

Aiming to give to the Convention on Biological Diversity the same scientific background IPCC gives to the Convention on Climate Change, a leading group of experts launched in January/06 a Consultative Process towards the establishment of an International Mechanism of Scientific Expertise on Biodiversity/IMoSEB. The goal of the consultative process was to assess the need, scope, and possible forms of an IMoSEB with the following elements: intergovernmental component; independence; competence, representativeness (opinions, disciplines, and regions); peer review; transparency and policy relevance. This panel is expected to determine what kind of biodiversity information is needed by decision-makers in many fields with an influence on biodiversity - including industry, fisheries, transportation, and parks management.

Along 2006 an interim Secretariat promoted an open consultative process aiming to establish a common interface between expertise and decision making. This process has now moved to a regional level, and the options being considered are: a) to establish a partnership of existing mechanisms delivering science to national \& international decision-making bodies; b) a new mechanism with intergovernmental and nongovernmental components; c) Invite IPCC to consider developing a biodiversity component to their activity; d) Strengthen existing networks of scientists to feed science into various fora through a small coordination mechanism. 
The aims of IMoSEB are very laudable, but it is difficult to say if they are achievable. It is difficult enough getting support for existing international organizations that are doing practical things, for instance GBIF, Catalog of Life, Biodiversity International (formerly IPGRI), DIVERSITAS, FAO, GTI and UNEP, and it is important not to undermine their work. So IMoSEB must have clear guidelines and boundaries in such a way that it will come to support these other organizations not to compete with them. We also have a very limited Biodiversity science work force - the more bodies like this that we establish - the more we dilute the actual time devoted to science.

Another strategy would be a bottom-up approach rather than a top-down approach, with a strong biodiversity discussion in disciplines like Taxonomy, Ecology and Genetics that meet at regular intervals to produce a combined report on the state of biodiversity. IMoSEB could be the coordinating mechanism to bring together these disciplinary fora.

Considering all effort developed by the BIOTA/FAPESP Program along the last eight years, we think that the last option would be the most interesting for us. But, as far as we know, eighteen months after the international discussion about IMoSEB started, it is not being discussed by Brazilian scientists and/or government, although biodiversity is one of our most valuable patrimonies!

\section{Carlos Alfredo Joly}

Department of Botany, Biology Institute, State University of Campinas, CP 6109, CEP 13083-970, Campinas, SP, Brazil and Member of the Stirring Committee of the BIOTA/FAPESP Program 